\title{
Publisher Correction: Pharmacological targeting of the unfolded protein response for disease intervention
}

Claudio Hetz (D), Jeffrey M. Axten (D) and John B. Patterson (iD)

Correction to: Nature Chemical Biology https://doi.org/10.1038/s41589-019-0326-2, published online 18 July 2019

In the version of this Review Article originally published, there were two errors in Fig. 3a. The label for the second compound on the top left should read 'A-I06' instead of 'A-I09'. Furthermore, the chemical structure of MKC9989 was missing an oxygen in the coumarin ring and a hydrogen atom label for the aldehyde functionality. These errors have been corrected in the HTML and PDF versions of the paper.

a<smiles>O=S(=O)(/N=C/c1c(O)ccc2ccccc12)c1cccs1</smiles>
STF-083010
Original

RNase binders
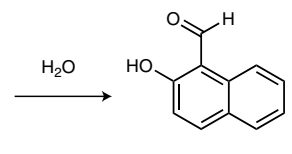

A-109<smiles>CN1CCN(C(=O)c2ccc(-c3ccc4c(C=O)c(O)ccc4c3)s2)CC1</smiles><smiles>COc1cc2c(C)c(CC(=O)N3CCOCC3)c(=O)oc2c(O)c1O</smiles>

MKC8866<smiles>Cc1cc(=O)oc2c(C=O)c(O)ccc12</smiles>

$4 \mu 8 \mathrm{c}$<smiles>O=c1oc2c(C3OCCCO3)c(O)ccc2c2c1CCNC2</smiles>

$-109$

Corrected

a<smiles>O=S(=O)(/N=C/c1c(O)ccc2ccccc12)c1cccs1</smiles>

STF-083010

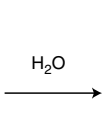<smiles>O=Cc1c(O)ccc2ccccc12</smiles>

A-106<smiles>Cc1cc(=O)oc2c(C=O)c(O)ccc12</smiles>

$4 \mu 8 \mathrm{c}$<smiles>COCCOCCC1=C(C)c2cc(OC)c(O)c(C(C)=O)c2CC1=O</smiles>

MKC9989<smiles>O=c1oc2c(C3OCCCO3)c(O)ccc2c2c1CCNC2</smiles><smiles>CN1CCN(C(=O)c2ccc(-c3ccc4c(C=O)c(O)ccc4c3)s2)CC1</smiles><smiles>COc1cc2c(C)c(CC(=O)N3CCOCC3)c(=O)oc2c(C=O)c1O</smiles>

MKC8866<smiles>COCCOCCc1c(C)c2cc(OC)c(O)c(C=O)c2oc1=O</smiles>

MKC9989

Fig. 3 | Original and Corrected. 